Yi, Y., Xu, W., Gupta, J.K., Guity, A., Marmion, P., Manning, A., Gulick, B., Zhang, X., and Chen, Q. 2009. " Experimental study on displacement and mixing ventilation systems for a patient ward," HVAC\&R Research,15(6), 1175-1191.

\title{
Experimental Study on Displacement and Mixing Ventilation Systems for a Patient Ward
}

\author{
Yonggao Yin, \\ Weiran Xu, Ph.D. \\ Jitendra K. Gupta, Student Member ASHRAE \\ Arash Guity, \\ Paul Marmion, Member ASHRAE \\ Andy Manning, Ph.D. \\ Bob Gulick, Member ASHRAE \\ Xiaosong Zhang, Ph.D. \\ Qingyan Chen*, Ph.D., Fellow ASHRAE
}

Yonggao Yin is a doctoral student at Southeast University, Nanjing, China, Weiran Xu an Applied Engineer Consultant at Mantor Graphics, Marlborough, MA, Jitendra Gupta a Ph.D. candidate at Purdue University, West Lafayette, IN, Arash Guity a mechanical engineer at Mazzetti \& Associates Co., San Francisco, CA, Paul Marmion a senior principal at Stantec, Vancouver BC, Andy Manning is a senior engineer in Mantor Graphics, Marlborough, MA, Bob Gulick a senior principal at Mazzetti \& Associates Co., San Francisco, CA, Xiaosong Zhang a professor at Southeast University, Nanjing, China, and Qingyan Chen a professor at Purdue University, West Lafayette, IN. Yonggao Yin was a visiting scholar at Purdue University when this study was performed.

*Corresponding author: yanchen@purdue.edu

\section{ABSTRACT}

In hospital patient wards, exhalation flow from a patient with airborne infectious diseases can impose health risks to caretakers and visitors. Usually, mixing ventilation has been used to remove the airborne contaminants, but now displacement ventilation is becoming popular in such wards. This study investigated experimentally the performance of both mixing and displacement ventilation by using a full-scale environmental chamber to simulate a one-person patient ward. Our results show that displacement ventilation may or may not provide a better air quality in the ward, depending on the location of the exhaust in relation to the restroom. A tracer gas $\left(S F_{6}\right), 1 \mu m$ particles, or $3 \mu \mathrm{m}$ particles can be used to simulate contaminants breathed out by a patient since these contaminants generate similar contaminant distributions in the ward except in the areas close to the contaminant source and the exhaust adjacent to the restroom, where the flow may be unstable. The experimental data obtained from this study can be used to validate the CFD models.

KEYWORDS: Displacement ventilation, mixing ventilation, particle dispersion, contaminant, patient ward

\section{INTRODUCTION}

Effective ventilation in hospital wards is very important to control respiratory disease transmission through air motion (Tang et al., 2006). The catastrophic number of casualties caused by the worldwide outbreak of the Severe Acute Respiratory Syndrome (SARS) in 2003 may have been the result of poor ventilation (Li et al., 2004). Thus, ventilation systems in hospital wards should be improved to control airborne infectious disease transmission (Gamage et al., 2005). Many studies have been conducted for ventilation in different hospital facilities. A panel led by Li et al. (2007) reviewed 40 original studies and found strong and sufficient evidence of the association between ventilation, air movements in buildings and the transmission/spread of infectious diseases such as measles, tuberculosis, chickenpox, influenza, smallpox and SARS. Beggs et al. (2008) conducted a review on designing ventilation systems for hospital wards and other multibed rooms. The review found the bioaerosol depends on air distribution method and the clinical role of general ward ventilation may have been underestimated. Through improved ward ventilation, it may be possible to reduce environmental contamination and thus reduce nosocomial infection rates. Ho et al. (2009) found that the diffuser location of a ventilation system can play an important role in thermal comfort and air quality in an operating theater. However, 
the downward laminar flow airflow pattern recommended by the CDC was impossible to achieve due to turbulent flow mixing and thermal buoyancy (Qian et al. 2008). It is not easy to design hospital ward with good ventilation. Li et al. (2007a) found only $97 \%$ of the new isolation rooms built in Hong Kong meet the design criteria and Saravia et al. (2007) found the situation is much worse in the USA with only $32 \%$ of the isolation rooms meeting the design criteria. If not properly designed and maintained, ventilation system could be a source of contamination in hospitals (Wu et al. 2007).

Commonly used ventilation systems in hospital wards are the mixing ones, but displacement ventilation systems are now becoming popular (Tang et al., 2006). Although many studies on ventilation system performance are available for classrooms (Norback and Nordstrom, 2008), offices (Pereira et al., 2008) and homes (Hamdani et al. 2008), and a comparative experimental study on displacement and mixing ventilations was conducted for an office case (He et al., 2005), very few have been done for hospital wards. Thus, there is a paucity of good quality data from which to make important decisions and develop guidelines regarding the ventilation of general ward spaces (Beggs et al. 2008). No consensus has yet been reached as to whether displacement ventilation systems should be used in patient wards and isolation rooms. Brohus and Nielsen (1996) recommended displacement ventilation for better contaminant removal. However, Qian et al. (2006) did not suggest the use of the displacement ventilation. Perhaps the two studies were conducted under different conditions. Therefore, it is essential to conduct a systematic study to compare both displacement and mixing ventilation systems for a patient ward under similar conditions.

At present, patient wards with mixing ventilation usually have an exhaust grille installed in the lower part of the restroom door, and some air is extracted through the grille to keep the restroom at a lower pressure than in the wards. If displacement ventilation is used in patient wards, the exhaust should be placed at ceiling level. However, many designs neglect to move the exhaust location. It is necessary, therefore, to examine whether exhaust location is important for ventilation performance.

In addition, tracer gases (Norback and Nordstrom, 2008; Brohus and Nielsen, 1996) and particles (Zhang and Chen, 2009) have often been used in investigating airborne contaminant dispersion, but it is not certain if they would produce the same results for infectious disease transmission in a patient ward. Thus, it is necessary to conduct a comparative study.

Furthermore, Computational Fluid Dynamics (CFD) models are being used for optimizing ventilation system design in a patient ward. Since the flow in a patient room is very complicated, the CFD models must be validated in order to produce reliable results. However, no high quality data with sufficient information on boundary conditions are available from the literature. Therefore, it is important to have such data available for validating the CFD models.

In order to conduct research to solve the above-mentioned problems, this investigation used an environmental chamber to simulate a one-person patient ward, in which the patient could breathe or cough out infectious disease viruses. The objectives of this investigation were (1) to compare the performance of mixing and displacement ventilation systems; (2) to verify whether the exhaust location to the restroom would affect the ventilation performance; (3) to assess the differences in using tracer gas or a different size of particle for simulating infectious disease transmission in the ward; and (4) to provide high quality experimental data for validating the CFD models for ventilation design or analysis for patient wards.

\section{EXPERIMENTAL SETUP AND METHOD}

\section{Experimental Setup}

This investigation simulated a full-scale, one-person patient ward $(4.90 \mathrm{~m}(193 \mathrm{in}$. $) \times 4.32 \mathrm{~m}(170 \mathrm{in}$. $) \times 2.72 \mathrm{~m}(107$ in.)) as shown in Figs. 1(a) and (b) by using an environmental chamber as depicted in Figs. 1(c) and (d). The environmental chamber can provide controlled air supply with different airflow rates, temperatures, and humidities. The chamber had a good insulation on the walls, ceiling, and floor so the temperatures were stable. The ward was furnished with one bed, cabinets, a TV set, and a piece of medical equipment. This ward had one patient lying on the bed and one caretaker standing on the right side of the patient. Table 1 shows the dimensions and heat generated by all the sources in the ward. Please note that the heat generated by the patient and caretaker may have been a little higher than the actual values. This is because the actual power inputs for the heat sources were higher than the labeled values. 
This investigation studied a mixing and a displacement ventilation system for this ward. The mixing ventilation was created by supplying air from a four-way overhead diffuser as shown in Fig. 2(a). The air was extracted from two exhaust grilles as shown in Fig. 1(a): an auxiliary exhaust adjacent to the restroom and a main exhaust in the ward. The auxiliary exhaust is normally installed in the lower part of the restroom door to keep the air pressure in the restroom lower than in the ward, as shown in Fig. 3. The main exhaust can be installed in the upper part of a wall, as shown in Fig. 1(a), or in the lower part of a wall. Since the mixing ventilation would mix air evenly, the exhaust locations should not have a major impact on the ventilation performance. The displacement ventilation was created by supplying air through the sidewall displacement diffuser installed on the floor level, as shown in Fig. 1. The diffuser was a large, perforated panel, as shown in Fig. 2(b), to minimize supply air jet for reducing drafts. The displacement ventilation should extract air at the ceiling level, such as the main exhaust shown in Fig. 1(a). However, many existing designs did not move the auxiliary exhaust to the upper part of the wall adjacent to the restroom. Thus, it is a very likely scenario that the displacement ventilation may have the main exhaust in the upper part of the ward and the auxiliary exhaust in the lower part of the ward. Our investigation also studied the scenario with the auxiliary exhaust moved to the upper part of the wall adjacent to the restroom (see Fig. 3) to verify whether the auxiliary exhaust location would affect the ventilation performance.

The ventilation rate studied was either $4 \mathrm{ACH}(114 \mathrm{CFM})$ or $6 \mathrm{ACH}(171 \mathrm{CFM})$. A $6 \mathrm{ACH}$ ventilation rate was standard for patient wards. Since the displacement ventilation system is believed to produce a better air quality, its ventilation rate could be reduced to $4 \mathrm{ACH}$ to maintain the same indoor air quality as in the mixing ventilation. The auxiliary exhaust extracted $78 \mathrm{CFM}$ of air through the grille, and the main exhaust extracted the rest. The supply air temperature was $19.5^{\circ} \mathrm{C}$ for both systems.

In this study, 16 cases of measurements were conducted as summarized in Table 2 . The 16 cases were designed to systematically compare different ventilation scenarios. The cases were also designed to gradually increase the level of complexity in the thermo-fluid conditions so that a validation of the CFD models can be conducted to identify conditions that may cause discrepancies, if any. For example, Case 1L was simple isothermal case, which was designed to validate the CFD models for their ability to simulate isothermal flows. The six eight cases had the auxiliary exhaust in the lower level of the door adjacent to the restroom, while the second 10 cases had the auxiliary exhaust in the upper level, as shown in Fig. 3. These 16 cases can provide us sufficient data with which to evaluate the impact of the following parameters on ventilation performance in order to achieve the objectives. The parameters are

(1) Ventilation systems (mixing vs. displacement ventilation)

(2) Location of the auxiliary exhaust (Low level vs. high level)

(3) Supply air flow rate (displacement ventilation with air flow rates of $4 \mathrm{ACH}$ vs. $6 \mathrm{ACH}$ )

(4) Method to simulate contaminants (infectious disease viruses simulated by $\mathrm{SF}_{6}$ gas, $1 \mu \mathrm{m}$ particles, and 3 $\mu \mathrm{m}$ particles)

Considering that this work may also provide data for validating CFD models, the heat sources were designed to be released in rectangular boxes so that they can be easily simulated by CFD to eliminate errors that may be caused by complicated geometry.

This investigation focused on the contaminant dispersion from the patient to the rest of the room and on assessing the infection risk to the caretaker. A patient with an airborne infectious disease often releases respiratory viruses into the surroundings through breathing. Breathing is a transient process. However, it is difficult to make a transient measurement in a patient ward because a cough lasts less than one second and a breathing cycle two to three seconds, but measurements of virus concentration need tens of seconds. Hence, our investigation simplified the breathing as a constant process, which means that the virus release was simulated at a constantly releasing rate. For simplicity, our study simulated breathing by introducing a contaminant source at negligible velocity.

To simulate infectious disease viruses breathed out by a patient, this study used a tracer gas, sulfur hexafluoride or $\mathrm{SF}_{6}$, and monosize particles of 1 or $3 \mu \mathrm{m}$ released at a constant rate at the mouth position of the patient. First, this investigation did not use larger particles as they may be deposited quickly on the floor and are not airborne. Also, the tracer gas could not contain any infectious disease viruses. The tracer gas was tested to see whether its concentration could be used to reasonably represent particle concentration. If so, it would be much easier to use tracer gas in future experiments or in CFD modeling to simulate infectious disease viruses. 
The $\mathrm{SF}_{6}$ tracer gas in a $1 \%$ solution was introduced from a large cylinder that can control stably the pressure to ensure a constant flow rate of $300 \mathrm{~mL} / \mathrm{min}$ to the ward. Considering that the background concentration of $\mathrm{SF}_{6}$ in the atmosphere was very low, the low flow rate would ensure a high quality of data while not disturbing the main flow in the ward.

The releasing rate of the particles depended on the background concentration of the particles in the supply air and room air. Our experiment was to adjust the releasing rate to ensure that the particle concentration in the room would be at least 100 times higher than the background concentration. This would eliminate the influence of the background particle concentration on the data. The particles were generated by a condensation Monodisperse Aerosol Generator (TSI Model 3475). The particles were produced by Di-Ethyl-Hexyl-Sebacat with a density $912 \mathrm{~kg} / \mathrm{m}^{3}$. Two different mono-sizes of particles were generated, 1 and 3 micron meters with a standard deviation of particle diameter of less than 1.15, which simulate infectious disease viruses. The particles were liquid aerosols with a long and stable aerosol lifetime and had good optical properties for our particle counter and sizer.

All the measurements were conducted under steady-state conditions. This implies that the breathing and coughing processes were continuous, which are of course not true in reality. However, the steady state would help to establish stable conditions for measurements with high accuracy.

To simulate the disease viruses from breathing, the $\mathrm{SF}_{6}$ was introduced into a sponge sphere with a diameter of $0.04 \mathrm{~m}$, so the tracer gas was released into the patient ward at a very low velocity and a constant releasing rate.

\section{Experimental Procedure}

The ventilation system ran for more than 14 hours to achieve steady airflow and temperature distributions in the ward. At the steady condition, the room air temperature was constant over one hour. The experiment measured the air velocity and temperature at eight poles around the patient bed (as shown in Fig. 4(a)) as well as the air temperature at the exhausts with omni-directional anemometers. The exact measurement locations are shown in Fig. 4(b). The measurements were conducted at seven heights in each pole for the air velocity and temperature, namely 0.12 (4.7 in.), 0.35 (13.8 in.), 0.85 (33.5 in.), 1.35 (53.1 in.), 1.85 (72.8 in.), 2.35(92.5 in.), and 2.60 $\mathrm{m}(102.4$ in.) from the floor. The 56 omni-directional anemometers were connected with a multiple-channel data logger to acquire air velocity and temperature data at the 56 points at the same time. The anemometers had an accuracy of $0.2 \mathrm{~K}$ for air temperature and $0.02 \mathrm{~m} / \mathrm{s}$ for air velocity. This investigation used two ultrasonic anemometers to check the accuracy of the omni-directional anemometers. Table 3 shows the comparison of measured air velocities at some locations in the room by the two types of anemometers. Generally, the omnidirectional anemometers should be applied for a velocity higher than $0.07 \mathrm{~m} / \mathrm{s}$ because the false convection from the probes can be significant at a low velocity. However, the comparison indicates that the omni-directional anemometer gave quite acceptable results as the differences were less than $0.02 \mathrm{~m} / \mathrm{s}$, compared with those of the ultrasonic anemometers. The air velocity and temperature were measured at each location for 40 minutes, with a sampling frequency of $10 \mathrm{~Hz}$.

After the airflow reached the steady state, the tracer gas/particles were released into the ward. It usually took two to three hours to achieve a steady state of the contaminant concentration distribution after the tracer gas/particles were released into the ward. Then the measurements of the contaminant concentration could start. The $\mathrm{SF}_{6}$ and particle concentrations were measured in five poles in the room, as shown in TG1 through TG5 in Fig. 5(a). At each pole, the measurements were taken at six heights: 0.12(4.7 in.), 0.60(23.6 in.), 1.10(43.3 in.), 1.60(63 in.), 2.10 (82.7 in.), and $2.60 \mathrm{~m}$ (102.4 in.) from the floor. The data resolution was not very fine but sufficient to provide a good picture of the contaminant distributions in the ward.

The contaminant concentration was measured 10 to 25 times at each location to obtain the mean concentration and standard deviation. Each time took 12 seconds to obtain a data entry. Thus, to measure the contaminant concentrations at the 30 locations for one case usually took three to four hours. By using a pump that can switch the sampling air from one location to another and by setting up the control software to monitor the particles, the experimental measurements were nonintrusive. A photoacoustic multi-gas analyzer (INNOVA model 1312) with a multipoint sampler (INNOVA model 1309) was used to measure the $\mathrm{SF}_{6}$ concentration with an accuracy of $0.001 \mathrm{ppm}$. An aerodynamic particle sizer spectrometer (TSI model 3321) was used to measure the particle concentration with a range from 0.898 to $1.114 \mu \mathrm{m}$ for $1 \mu \mathrm{m}$ particles and from 2.642 to $3.523 \mu \mathrm{m}$ for $3 \mu \mathrm{m}$ particles.

The $\mathrm{SF}_{6}$ or particle concentrations were normalized by 


$$
\varepsilon=\frac{C_{P}-C_{s}}{C_{e}-C_{s}}
$$

where $C_{p}$ and $C_{s}$ are the tracer-gas or particle concentrations at the measuring location and the ventilation supply inlet, respectively, and $C_{e}$ is the averaged tracer-gas or particle concentration of the two ventilation exhausts determined by

$$
C_{e}=R_{C} /\left(G_{M}+G_{B}\right)
$$

where $G_{M}$ and $G_{B}$ are the airflow rate through the main and restroom exhausts and $R_{C}$ is the releasing rate of the tracer gas or particles.

After the completion of the contaminant concentration measurements, the air velocity and temperature were measured again at the exhausts to check to see if they were the same as when the experiment started. If the difference between the two measurements was less than $0.2 \mathrm{~K}$, the experiment for that case was complete.

\section{RESULTS}

\section{Repeatability of the Experimental Measurements}

One major concern of experimental studies is if a measurement can be repeated. Therefore, before discussion of the experimental data, it is essential to check the repeatability of our experiment. The repeatability was conducted by measuring Case $5 \mathrm{H}$ three times on different days that produced three different sets of data (Cases $5 \mathrm{Ha}, 5 \mathrm{Hb}$, and $5 \mathrm{Hc}$ on Table 2). Although all the walls of the environmental chamber had good thermal insulation and were situated in an air-conditioned laboratory, the wall temperatures were not constant and differed by up to $0.3 \mathrm{~K}$. The temperature changes were mainly caused by the radiation from the laboratory enclosure that was exposed to outdoor air, and it was impossible to keep the air temperature of the laboratory at an absolutely constant level. In spite of this, Fig. 5 shows that the measured profiles of air temperature, velocity, and tracer gas concentration at selected locations were repeatable. The temperature differences were less than 0.2 $\mathrm{K}$. The differences in the air velocity and $\mathrm{SF}_{6}$ concentration were within the standard deviations of a single measurement. Hence, the results indicate a good repeatability for our experiment.

\section{Comparison of the Displacement and Mixing Ventilation with the Low Level Exhaust at Different Ventilation Rates}

The first objective of this investigation was to compare the performance of mixing and displacement ventilation systems. Case $2 \mathrm{~L}$ is a typical mixing ventilation (MV) system used at present for a patient ward that has an overhead supply, a main exhaust, and an auxiliary exhaust at the low level through the restroom door. Please refer to Figs. 1(a) and 3 for more information. When displacement ventilation is used, many designs at present replace the overhead diffuser with a sidewall diffuser and the main exhaust is placed close to the ceiling level. However, the auxiliary exhaust may still be at the same location as that for the mixing ventilation. Case 3L was designed for such a displacement ventilation system since many designers believe that displacement ventilation could generate better air quality than the mixing ventilation. Thus, the ventilation rate for the displacement ventilation can be reduced from $6 \mathrm{ACH}$ to $4 \mathrm{ACH}$ as in Case 4L.

Fig. 6(a) compares the dimensionless temperature profiles in the three cases. The displacement ventilation has temperature stratification in the lower part of the room (1 m above the floor). The temperature gradient for 4 $\mathrm{ACH}$ was slightly smaller than that for $6 \mathrm{ACH}$ because most of the air was extracted through the low level exhaust of the restroom door. This in turn led to a much more uniform temperature distribution in the upper part of the room. The temperature distribution in the room with the mixing ventilation was rather uniform. The results show that the top part of pole 1 was directly in the downstream of the cold jet from the overhead diffuser.

Fig. 6(b) illustrates the velocity profiles at the five poles around the patient bed. The mixing ventilation led to a higher air velocity in the room compared with that of the displacement ventilation. However, the velocity in the room was generally lower than $0.2 \mathrm{~m} / \mathrm{s}$, so the two ventilation systems were not likely to generate a draft. By carefully comparing the velocity distributions at the two supply air flow rates for the displacement ventilation, the velocity distribution and magnitude were almost identical except in the area very close to the diffuser. 
The contaminant concentration at breathing level for the displacement ventilation was much higher than that for the mixing ventilation although it was lower in the region close to the floor, as shown in Fig. 6(c). Therefore, the displacement ventilation would not provide a better air quality for the ward than would the mixing ventilation. Since the contaminant concentrations were normalized in the figure, dimensional $\mathrm{SF}_{6}$ concentration for the displacement ventilation with $4 \mathrm{ACH}$ was almost three times as high as that of the mixing system at the breathing level of a standing person ( $1.6 \mathrm{~m}$ above the floor). This is because most of the clean air was extracted through the auxiliary exhaust in the lower part of the door between the restroom and the ward. Without moving the exhaust to the upper part of the door, such displacement ventilation is a very poor design and should be avoided. The results also show that the flow in the upper part of the ward in the displacement ventilation was not stable. The $\mathrm{SF}_{6}$ concentration had a very large deviation in the region. This is particularly evident on the right side of the room. This investigation has not yet identified a reason for the instability. On the other hand, the flow in the region for the mixing ventilation was stable. The $\mathrm{SF}_{6}$ concentration was uniform throughout the room.

\section{Comparison of the Displacement and Mixing Ventilation with the High Level Exhaust at Different Ventilation Rates}

When the auxiliary exhaust was moved from the lower part to the upper part of the wall between the ward and the restroom, Case 2L became Case $1 \mathrm{H}$, Case $3 \mathrm{~L}$ turned into Case $2 \mathrm{H}$, and Case $4 \mathrm{~L}$ switched to Case $3 \mathrm{H}$, etc. For a better comparison, Case 4L, which had a low exhaust and had 4 ACH, was used in Fig. 6. As shown in Fig. 7 (a) and (b), the air temperature and velocity profiles for Case 4L (DV LE 4ACH) and Case 3H (DV HE 4ACH) had similar temperature and air velocity profiles. Again, the displacement ventilation case with $6 \mathrm{ACH}$ had a higher velocity only in the region near the inlet, compared with that with $4 \mathrm{ACH}$. By moving the auxiliary location, the air temperature and velocity profiles for the mixing ventilation were similar to those shown in Fig. 6.

However, the change in the auxiliary exhaust location made a huge difference to the contaminant distribution in the ward, as shown in Fig. 7 (c). The contaminant concentration profiles for the displacement ventilation with 4 $\mathrm{ACH}$ and low level exhaust (Case $4 \mathrm{~L}$ ) were plotted as a comparison. The $\mathrm{SF}_{6}$ concentration at the breathing level in the ward for the displacement ventilation with the high level exhaust was much lower than that for the mixing ventilation if the ventilation rate was the same (Cases $1 \mathrm{H}$ vs. $2 \mathrm{H}$ ). Even with the reduced ventilation rate of 4 $\mathrm{ACH}($ Case $3 \mathrm{H})$, the displacement ventilation could create an $\mathrm{SF}_{6}$ concentration level in the breathing zone comparable to that of the mixing ventilation with $6 \mathrm{ACH}(\mathrm{Case} 1 \mathrm{H})$. Case $2 \mathrm{H}$ with $6 \mathrm{ACH}$ created the cleanest indoor environment among the cases shown in the figure. It should be noted that the change in auxiliary exhaust location for the mixing ventilation did not have an impact on the $\mathrm{SF}_{6}$ concentration profiles.

\section{Comparisons of the Contaminants Simulated by $\mathrm{SF}_{6}$ and 1 and $3 \mu \mathrm{m}$ Particles}

Cases $3 \mathrm{H}, 4 \mathrm{H}$, and $5 \mathrm{Hc}$ were designed to be used in a study of a contaminant, simulated by the tracer-gas $\left(\mathrm{SF}_{6}\right)$, $1 \mu \mathrm{m}$ particles, and $3 \mu \mathrm{m}$ particles, breathed out by a patient. The other thermo-fluid conditions were the same.

Fig. 8 compares the contaminant concentration profiles measured in the five poles. The concentration in the upper part of the room was the highest with the $3 \mu \mathrm{m}$ particles for Poles 4 and 5 . The two poles were close to the contaminant source and the restroom exhaust, where the airflow was unstable, as discussed previously. Our experience shows that it was difficult to accurately measure the contaminant concentration in an environmental chamber with the equipment, which may not be suitable for large fluctuating concentrations. The differences in the other poles were more likely to be from measuring errors than were the differences between the tracer gas and particles. Furthermore, the shapes of the concentration profiles look similar. Thus, we may conclude that the tracer gas and the two different sizes of particles were almost the same for simulating the contaminant released by the patient.

\section{DISCUSSION}

In this experiment, we measured the air velocity and air temperature in 56 locations and the contaminant concentration in 30 locations in a ward under a steady state. The experiment also included detailed thermo-fluid boundary conditions and geometric information that can be used as input for CFD simulations. Thus, the data can be used for validating CFD models for their suitability for use in computing complex airflow in a patient ward.

Actual contaminants exhaled by patients are liquid droplets. However, Morawska (2006) showed that the droplets evaporate within a second and the contaminants become particle nuclei. The evaporation time is 
negligible compared with the time for transport and dispersion from a patient to a healthcare taker. That is why this study could assume the contaminants exhaled by the patient to be solid particles.

In fact, the particles will deposit to the wall surfaces and other surfaces due to diffusion, inertia, impaction, and gravitational settling. Deposition of these particles may cause altering the particle size distribution and an additional sink for the particles. Despite of the deposition, the shapes of the particle concentration profiles were similar to those of the tracer-gas profiles. For more information on particle deposition, please refer to our paper (Zhang and Chen 2009) for the deposition significance of different size of particles.

The injection of infection disease is rarely steady-state. Our study (Gupta et al. 2009) for coughing shows that a typical cough lasts for about 0.4 second. However, measurements of tracer-gas/particle concentration distributions for unsteady state are not practical and reliable. The response of any particle/tracer-gas transducer would be a few seconds. At present, we are using CFD to study the impact of the transient injection on the distributions and the results will be reported in our next paper.

Furthermore, please note that this study did not study the impact of moving objects on the contaminant distribution, such as the patient or the healthcare taker may walk around, the doors may open or close, a visitor may come and go, and the sheet and blanket may be changed. Thus, the results were valid for the geometry and thermo-fluid boundary conditions presented here. Any further implication of a condition not studied here should be avoided.

Due to the limited space available, this paper will not report all the data obtained from this investigation. The paper is organized to present the main objectives outlined in the introduction. Should a reader be interested in obtaining the data, please contact the corresponding author, who will provide detailed information.

\section{CONCLUSIONS}

This investigation conducted an experimental study on infectious disease transmission from a patient in a oneperson ward by using an environmental chamber. The study compared displacement ventilation with mixing ventilation. The measurements had good repeatability, and the major findings are as follows:

Displacement ventilation may produce a worse air quality in the breathing zone if the auxiliary exhaust is located at the lower part of the restroom door, compared with mixing ventilation. When the exhaust was relocated to the upper part of the wall between the ward and restroom, displacement ventilation with a lower ventilation rate (4 $\mathrm{ACH}$ ) can provide an equivalent level of air quality at the breathing zone as mixing ventilation at a higher ventilation rate $(6 \mathrm{ACH})$. Displacement ventilation with a high exhaust and $6 \mathrm{ACH}$ provided the best air quality in the breathing zone. The air velocity and temperature profiles look almost the same except in the area close to the diffuser between the two different ventilation rates for displacement ventilation.

The experimental results also showed the comparison of the distribution profiles of the contaminants - $\mathrm{SF}_{6}$ tracer gas, $1 \mu \mathrm{m}$ particles, and $3 \mu \mathrm{m}$ particles, which used to simulate the contaminants generated by the patient. The corresponding contaminant concentration profiles in the room look the same except in the areas close to the contaminant source location and restroom exhaust, where the flow was unstable.

The experimental data can offer detailed information to validate the CFD models and further the validated CFD models could be used for optimization design of hospital ward in other scenarios.

\section{ACKNOWLEDGEMENTS}

This research was supported by the Kaiser Foundation through the Healthcare Ventilation Research Collaborative and China's Scholarship Council. The first author would also like to thank Purdue University for hosting him as a Visiting Scholar at the time this study was conducted. We are in debt to Dr. Farhad Memarzadeh of the National Institutes of Health for his valuable advice throughout the research.

\section{NOMENCLATURE}

\section{Symbols}

$\mathrm{ACH}=$ Air Change time per Hour

$\mathrm{C}=$ Concentration $(\mathrm{ppm})$

$\mathrm{G} \quad=$ Airflow rate $(\mathrm{kg} / \mathrm{s})$ 


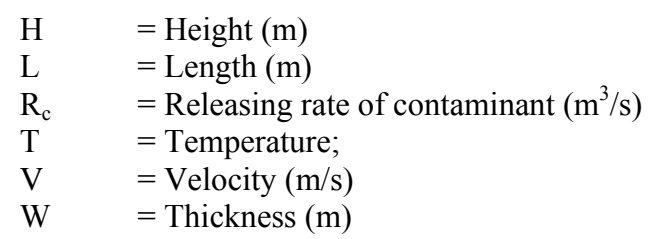

\section{Greek Symbols}

$\varepsilon \quad=$ Dimensionless concentration

$\theta \quad=$ Dimensionless air temperature

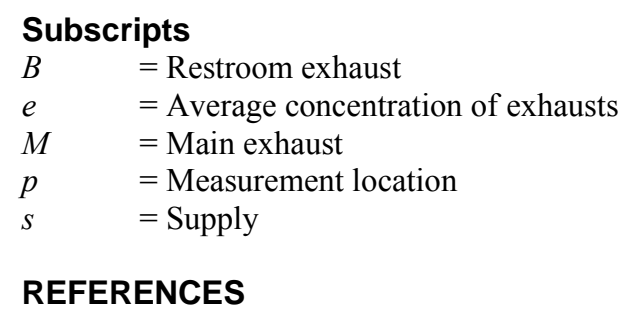

Beggs, C.B., K.G. Kerr, C.J. Noakes, E.J. Hathway, and P.A. Sleigh. 2008. The ventilation of multiple-bed hospital wards: Review and analysis. American Journal of Infection Control 36(4): 250-259.

Brohus, H., and P.V. Nielsen. 1996. Personal exposure in displacement ventilated rooms. Indoor Air 6(3): 157167.

Gamage, B., D. Moore, R. Copes, A. Yassi, and E. Bryce. 2005. Protecting health care workers from SARS and other respiratory pathogens: A review of the infection control literature. American Journal of Infection Control 33(2): 114-121.

Gupta, J.K., C.H. Lin, and Q. Chen. 2009. Flow dynamics and characterization of a cough. Accepted by Indoor Air.

Hamdani, S.E., K. Limam, M.O. Abadie, and A. Bendou. 2008. Deposition of fine particles on building internal surfaces. Atmospheric Environment 42(39): 8893-8901.

He, G., X. Yang, and J. Srebric. 2005. Removal of contaminants released from room surfaces by displacement and mixing ventilation: modeling and validation. Indoor Air 15(5): 367-380

Ho, S.H., L. Rosario, and M.M. Rahman. 2009. Three-dimensional analysis for hospital operating room thermal comfort and contaminant removal. Applied Thermal Engineering 29 (10): 2080-2092.

Li, Y., X. Huang, I.T.S. Yu, T.W. Wong, and H. Qian. 2004. Role of air distribution in SARS transmission during the largest nosocomial outbreak in Hong Kong. Indoor Air 15(2): 83-95.

Li, Y., G.M. Leung, J.W. Tang, X. Yang, C.Y.H. Chao, J.Z. Lin, J.W. Lu, P.V. Nielsen, J. Niu, H. Qian, A.C. Sleigh, H.J.J. Su, J. Sundell, T.W. Wong, and P.L. Yuen. 2007. Role of ventilation in airborne transmission of infectious agents in the built environment - A multidisciplinary systematic review. Indoor Air 17 (1): 218.

Li, Y., W.H. Ching, H. Qian, P.L. Yuen, W.H. Seto, J.K. Kwan, J.K.C. Leung, M. Leung, and S.C.T. Yu. 2007 a. An evaluation of the ventilation performance of new SARS isolation wards in nine hospitals in Hong Kong. Indoor and Built Environment 16 (5): 400-410.

Morawska L. 2006. Droplet fate in indoor environments, or can we prevent the spread of infection? Indoor Air 16: 335-347.

Norback, D., and K. Nordstrom. 2008. An experimental study on effects of increased ventilation flow on students' perception of indoor environment in computer rooms. Indoor Air 18(4): 293-300.

Pereira, M.L., G. Graudenz, A. Tribess, and W. Morawska. 2009. Determination of particle concentration in the breathing zone for four different types of ventilation systems. Building and Environment 44(5): 904-911

Qian, H., Y. Li, P.V. Nielsen, C.E. Hyldgaard, T.W. Wong, and A.T.Y. Chuang. 2006. Dispersion of exhaled droplet nuclei in a two-bed hospital ward with three different ventilation systems. Indoor Air 16(2): 111-128

Qian, H., Y. Li, P.V. Nielsen, and C.E. Hyldgaard. 2008. Dispersion of exhalation pollutants in a two-bed hospital ward with a downward ventilation system. Building and Environment 43 (3): 344-354.

Saravia, S.A., P.C. Raynor, and A.J. Streifel. 2007. A performance assessment of airborne infection isolation rooms. American Journal of Infection Control 35 (5): 324-331.

Tang, J.W., Y. Li, I. Eames, P.K.S. Chan, and G.L. Ridgway. 2006. Factors involved in the aerosol transmission of infection and control of ventilation in healthcare premises. Journal of Hospital Infection 64(2): 100-114. 
Wu, L.L., P. Diao, and Z.X. Zhou. 2007. Design of the ventilation system of central air conditioning in hospital: Control of hospital infection. Journal of Clinical Rehabilitative Tissue Engineering Research 11 (26): 51645166.

Zhang, Z., and Q. Chen. 2009. Prediction of particle deposition onto indoor surfaces by CFD with a modified Lagrangian method. Atmospheric Environment 43(2): 319-328.

Zhao, B., and J. Wu. 2007. Particle deposition in indoor environments: analysis of influencing factors. Journal of Hazardous Materials 147(1-2): 439-448. 


\section{Figure Captions:}

Fig. 1 Sketch and photos of the full-scale experimental chamber for simulating a ward.

(a) Configuration of the ward

(b) Dimensions of the ward

(c) Photo of the patient, bed, and caretaker

(d) Photo of the diffuser and TV set

Fig. 2 Photos of the diffusers.

(a) Overhead supply diffuser

(b) Displacement diffuser

Fig. 3 Locations of the auxiliary exhaust on the wall adjacent to the restroom.

Fig. 4 Measurement locations: Poles $1-8$ were for air velocity and temperature and TGs 1 - 5 for tracer gas or particles. (a) (b) (Unit: cm)

Fig. 5 Repeatability tests for Case $\mathbf{5 H}$ at three different measurements.

(a) Air Temperature

(b) Air Velocity

(c) Profiles of $\mathrm{SF}_{6}$ concentration

Fig. 6 Comparison of displacement and mixing ventilations with low level auxiliary exhaust through the restroom door. (H - height above the floor; MV - mixing ventilation, DV - displacement ventilation; MV 6ACH - Case 2L, DV 6ACH - Case 3L, DV 4ACH - Case 4L)

(a) Dimensionless air temperature $\left(\theta=\left(T-T_{s}\right) /\left(T_{e}-T_{s}\right)\right)$

(b) Air Velocity

(c) Dimensionless $\mathrm{SF}_{6}$ concentration $\left(\varepsilon=\left(C-C_{s}\right) /\left(C_{e}-C_{s}\right)\right)$

Fig. 7 Comparison of the displacement and mixing ventilation with high level auxiliary exhaust through the restroom door. (LE - low level exhaust, HE - high level exhaust; DV LE 4ACH - Case 4L, DV HE 4ACH - Case 3H, DV HE 6ACH - Case 2H, MV HE 6ACH - Case 1H)

(a) Dimensionless Air Temperature $\left(\theta=\left(T-T_{s}\right) /\left(T_{e}-T_{s}\right)\right)$

(b) Air Velocity

(c) Dimensionless concentration $\left(\varepsilon=\left(C-C_{s}\right) /\left(C_{e^{-}} C_{s}\right)\right)$

Fig. 8 Comparison of the contaminant concentration profiles in the ward by using the tracer gas (Case $3 \mathrm{H}$ ), $1 \mu \mathrm{m}$ particles (Case $4 \mathrm{H}$ ), and $3 \mu \mathrm{m}$ particles (Case $5 \mathrm{Hc}$ ). 


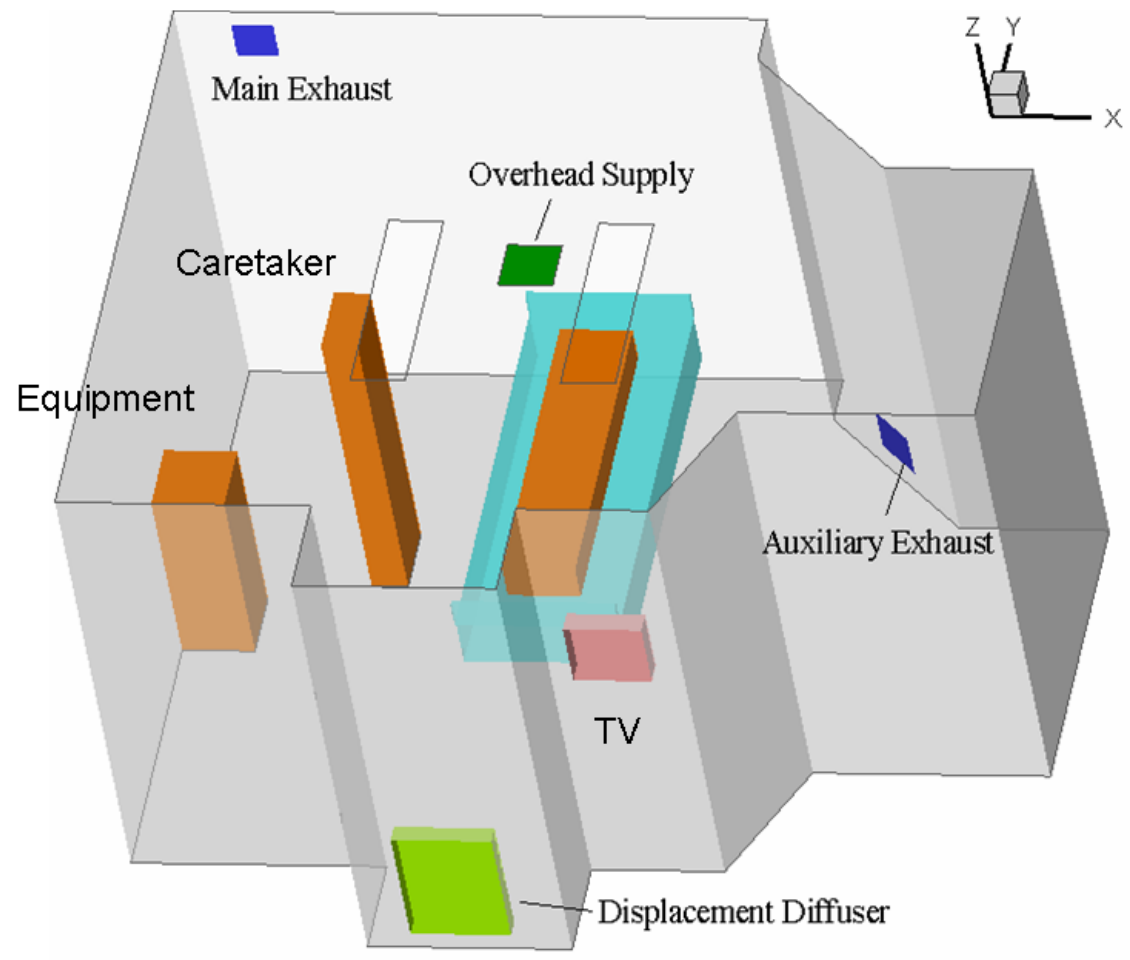

(a)

Fig. 1 Sketch and photos of the full-scale experimental chamber for simulating a ward. (a) Configuration of the ward 


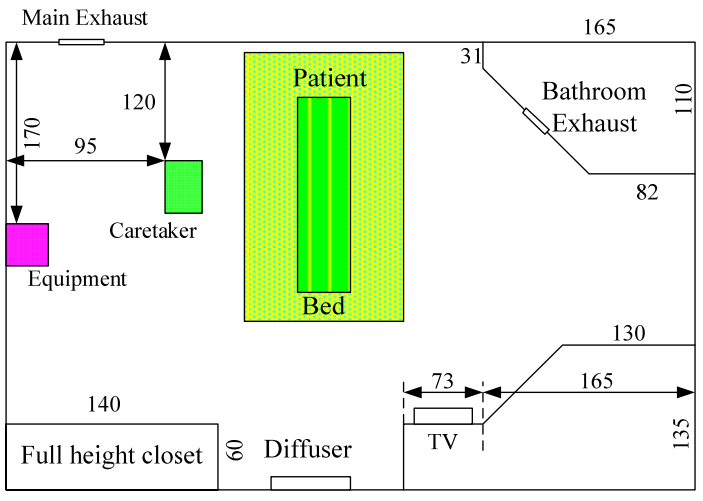

(b)

Fig. 1 Sketch and photos of the full-scale experimental chamber for simulating a ward. (b) Dimensions of the ward 


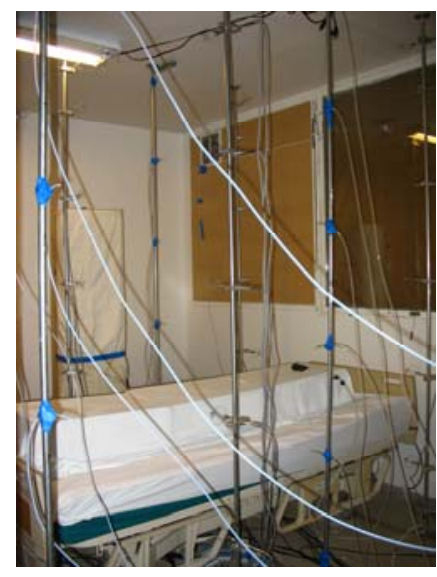

(c) Photo of the patient, bed, and caretaker

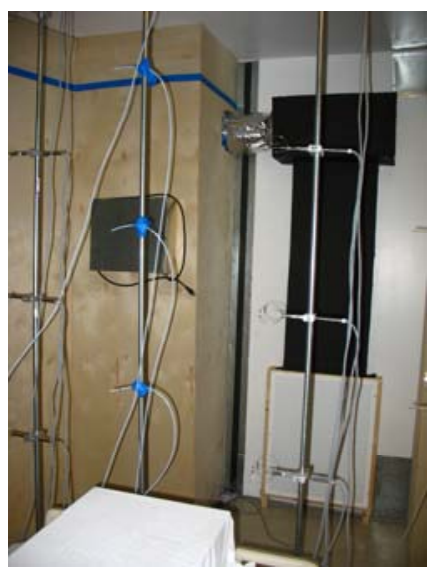

(d) Photo of the diffuser and TV set

Fig. 1 Sketch and photos of the full-scale experimental chamber for simulating a ward. (c) Photo of the patient, bed, and caretaker; (d) Photo of the diffuser and TV set 


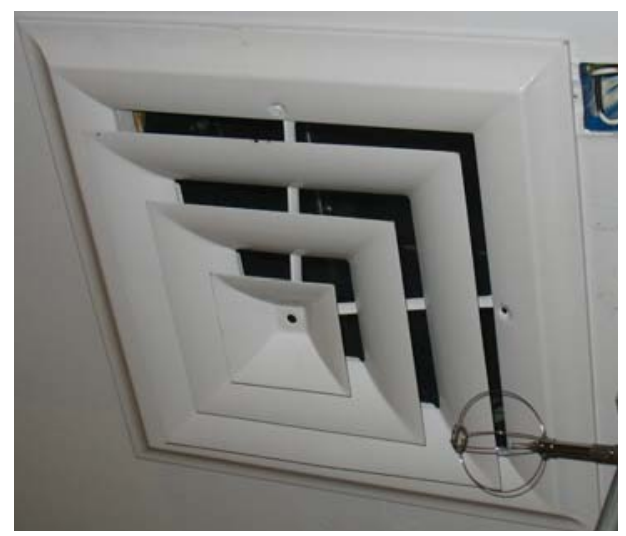

(a)

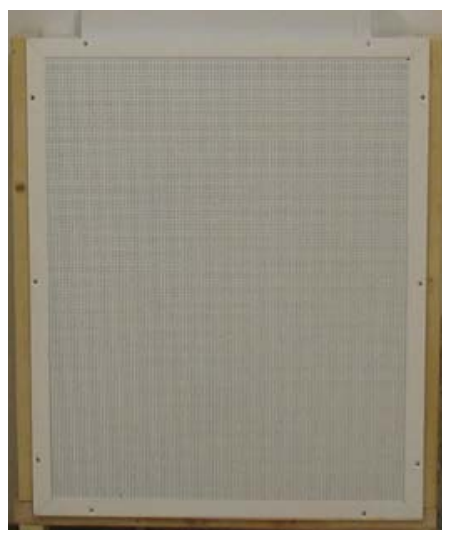

(b)

Fig. 2 Photos of the diffusers. (a) Overhead supply diffuser; (b) Displacement diffuser 


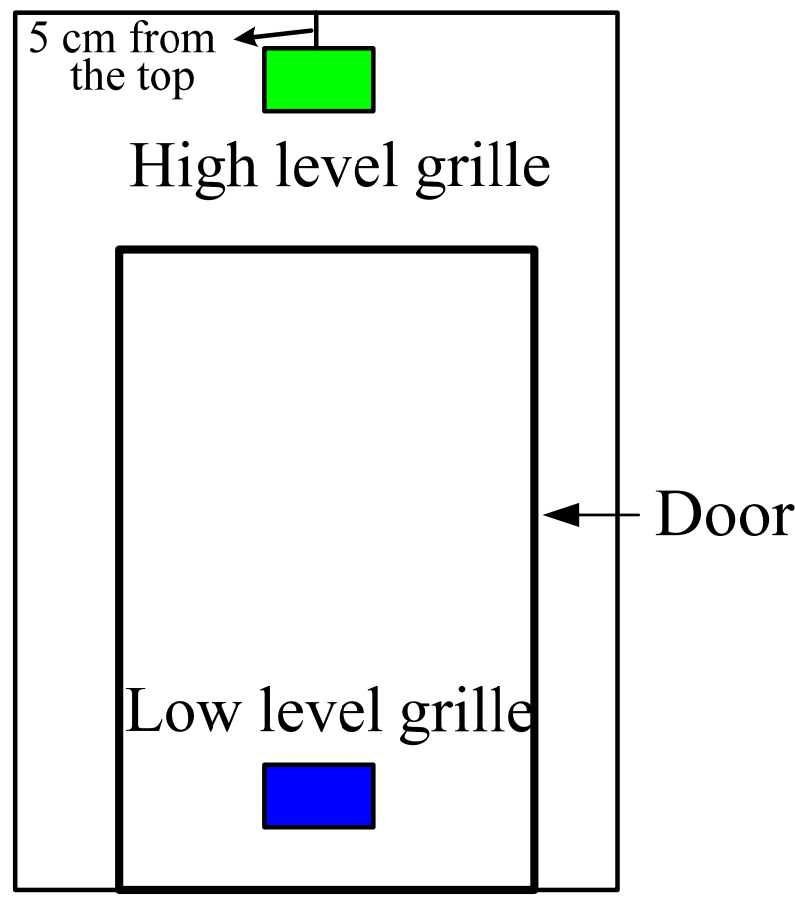

Fig. 3 Locations of the auxiliary exhaust on the wall adjacent to the restroom. 


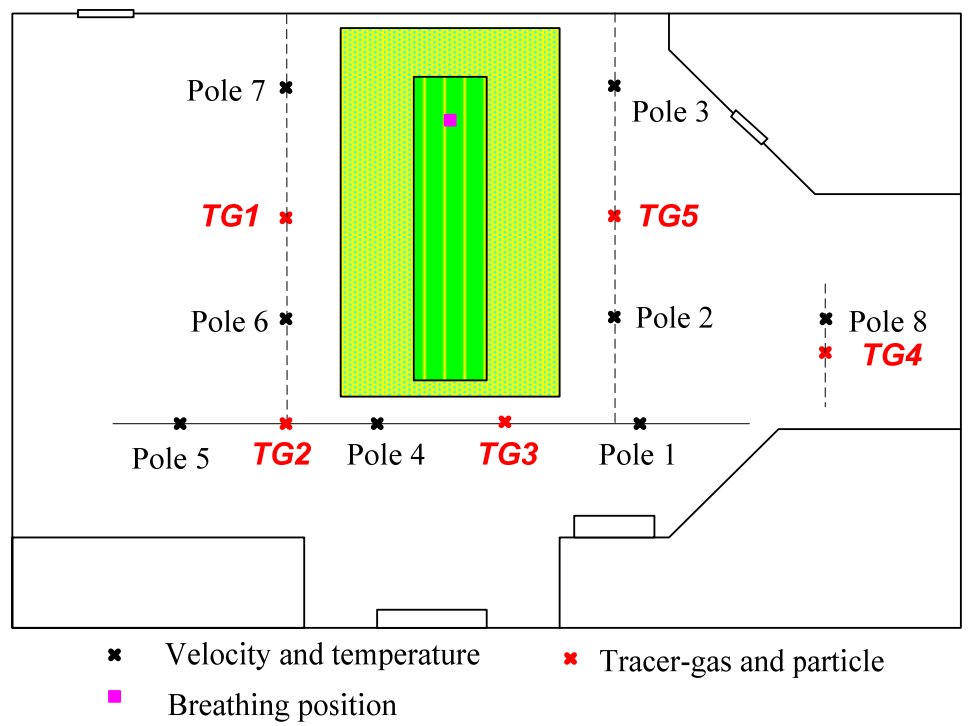

(a)

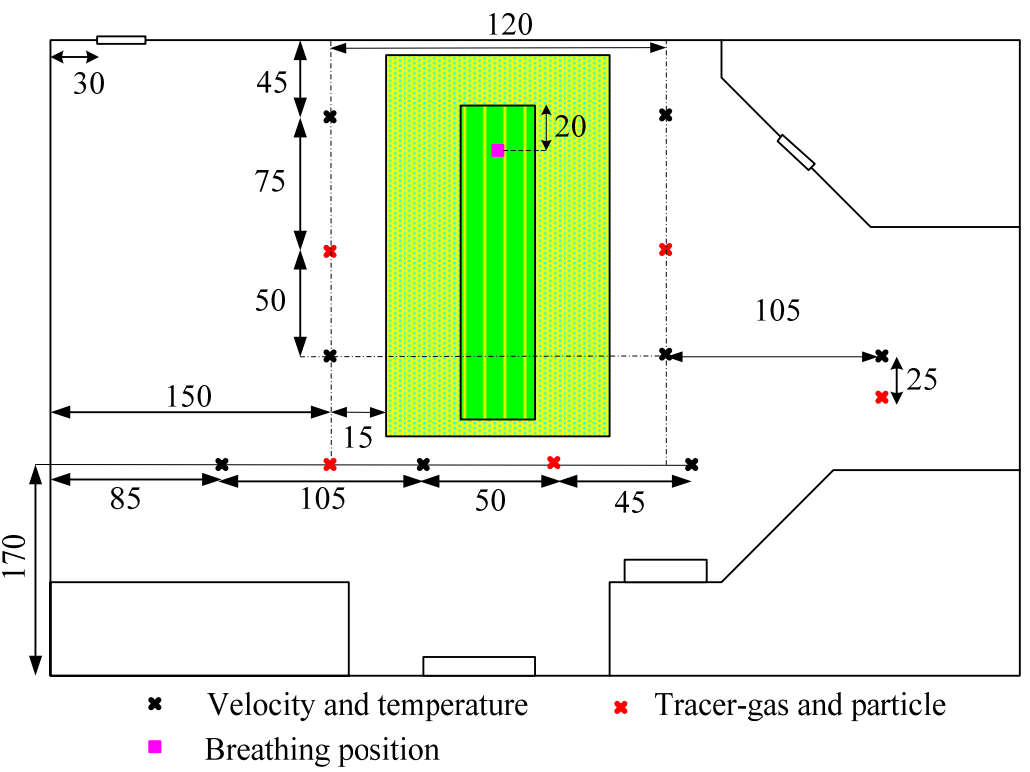

(b)

Fig. 4 Measurement locations: Poles $1-8$ were for air velocity and temperature and TGs 1 - 5 for tracer gas or particles. (a) (b) (Unit: cm) 
$\diamond$ Test 1 - Test $2 *$ Test 3
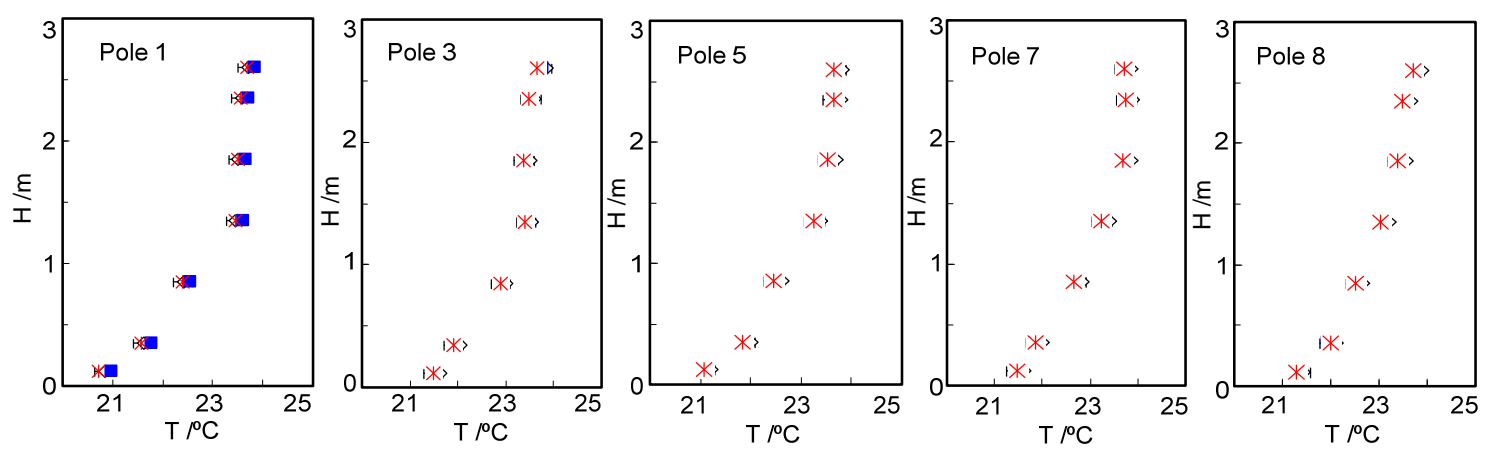

(a) Air Temperature
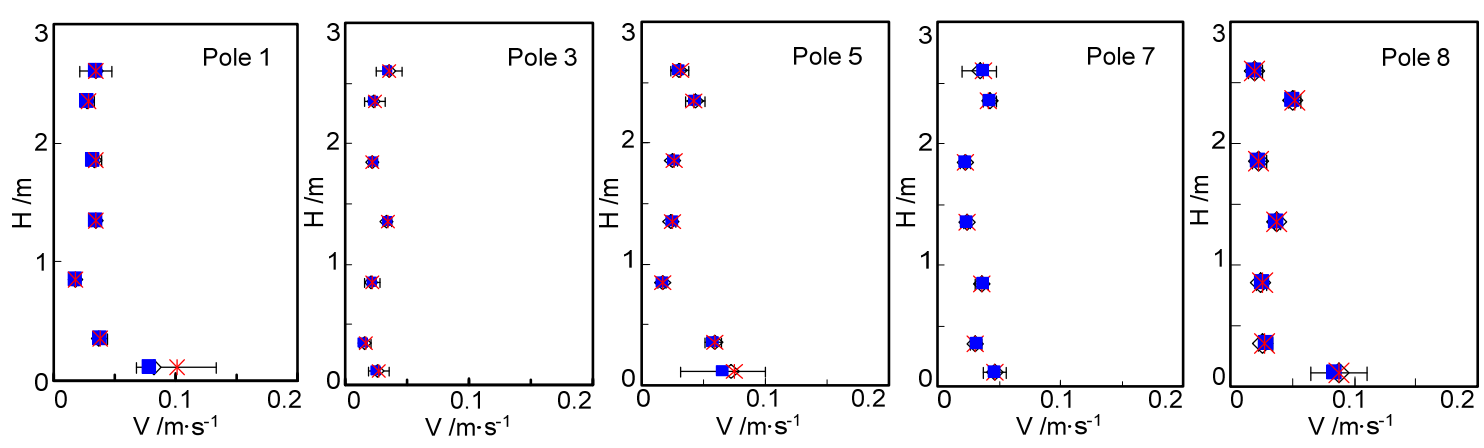

(b) Air Velocity
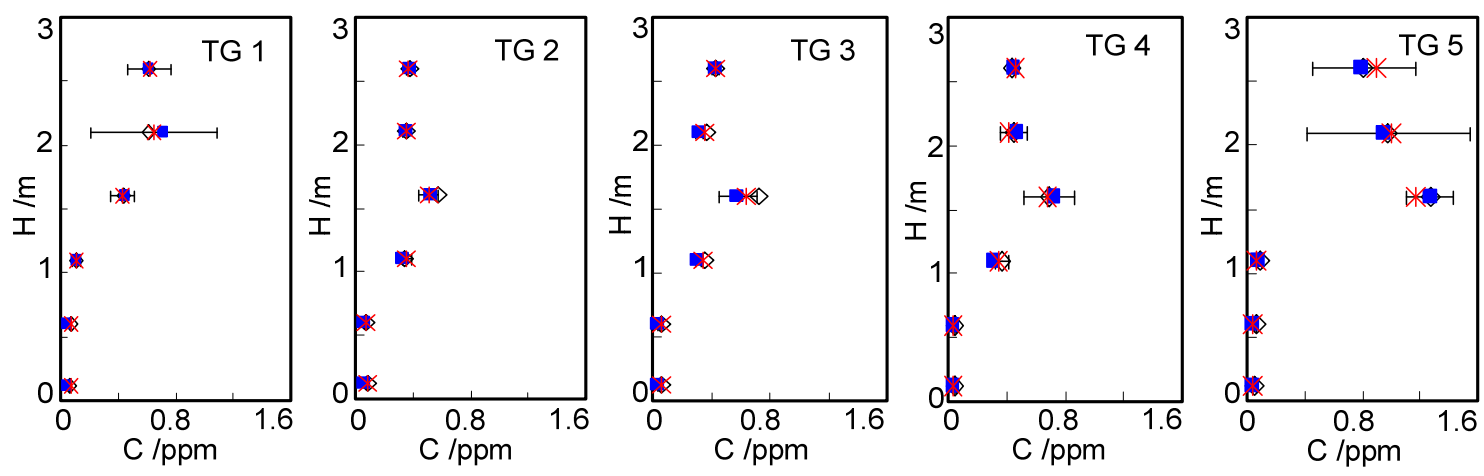

(c) Profiles of $\mathrm{SF}_{6}$ concentration

Fig. 5 Repeatability tests for Case $\mathbf{5 H}$ at three different measurements.

(a) Air Temperature; (b) Air Velocity; (c) Profiles of $\mathrm{SF}_{6}$ concentration 

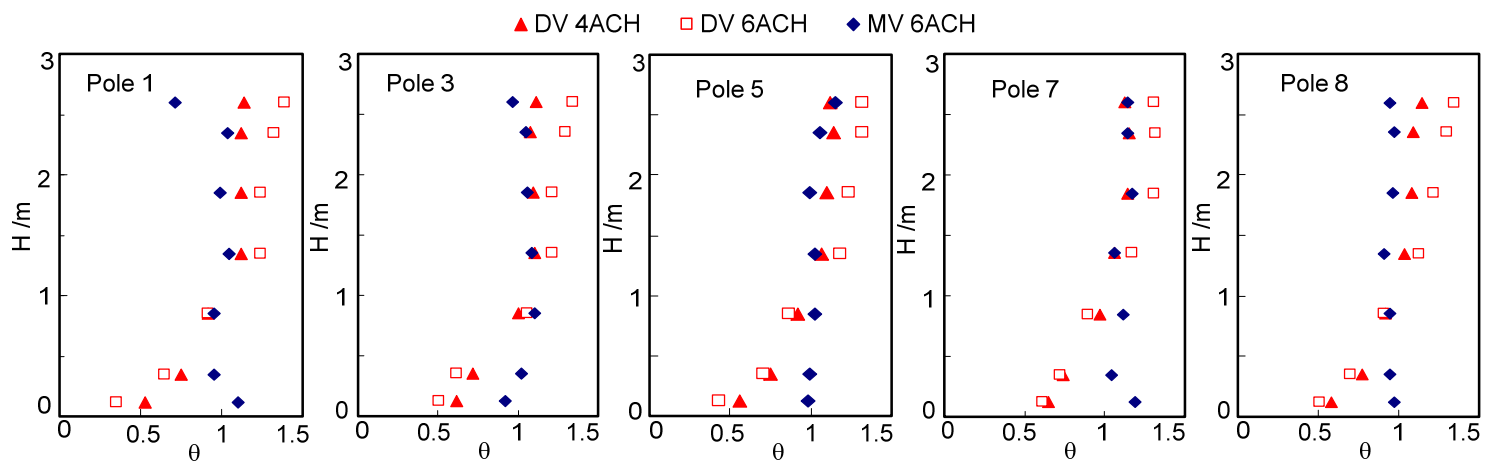

(a) Dimensionless air temperature $\left(\theta=\left(T-T_{s}\right) /\left(T_{e}-T_{s}\right)\right)$
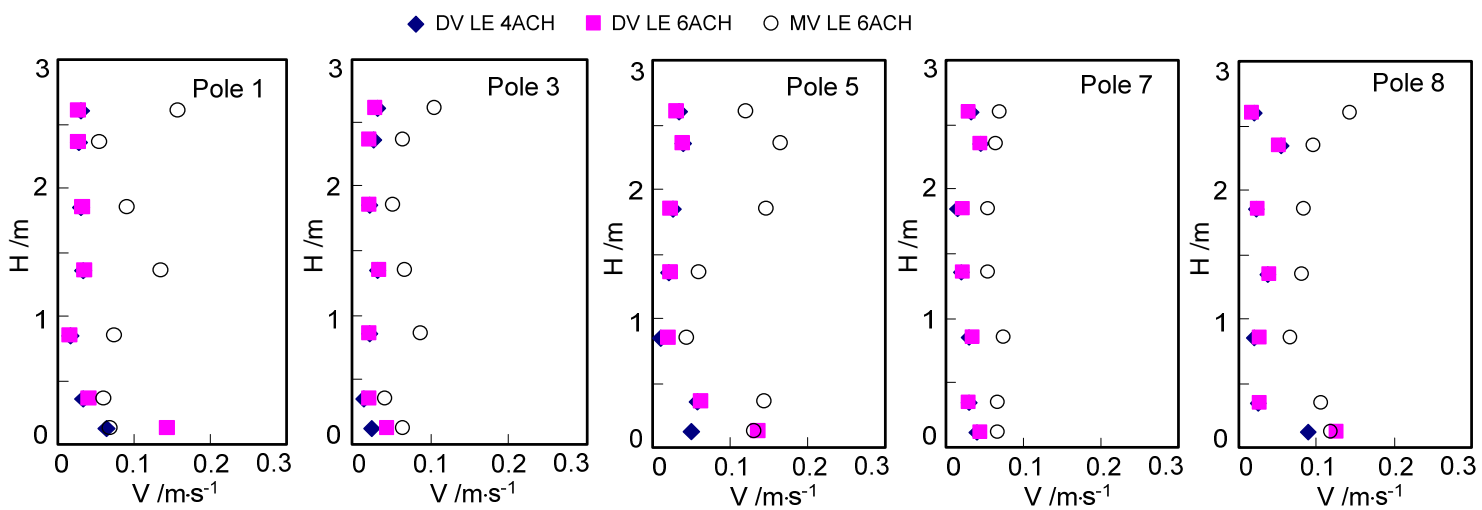

(b) Air Velocity
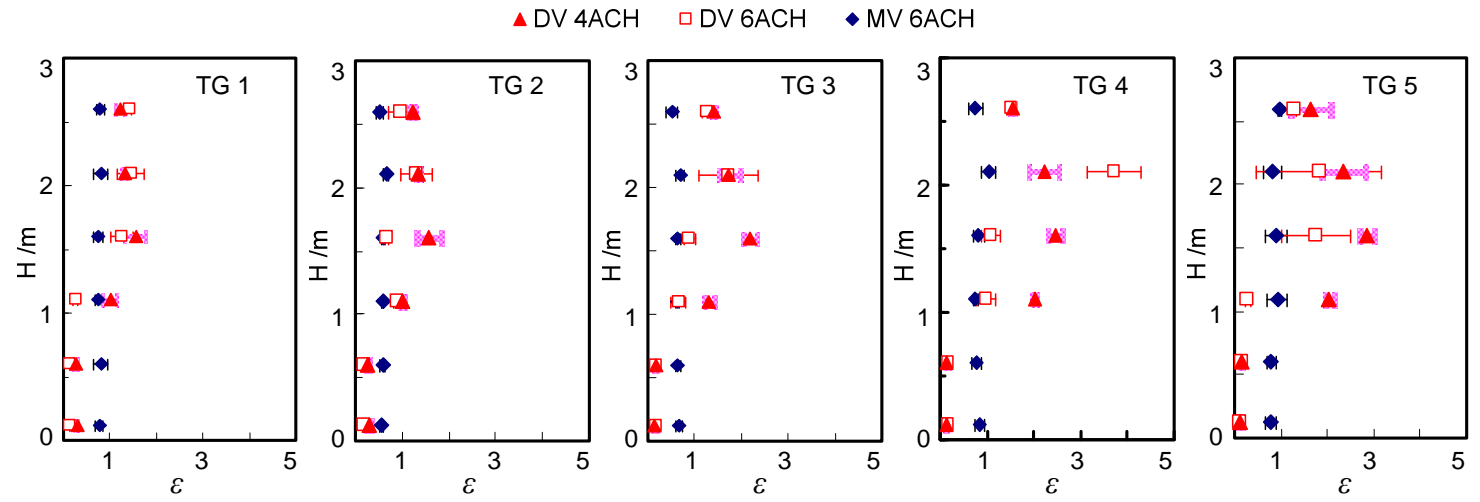

(c) Dimensionless $\mathrm{SF}_{6}$ concentration $\left(\varepsilon=\left(C-C_{s}\right) /\left(C_{e}-C_{s}\right)\right)$

Fig. 6 Comparison of displacement and mixing ventilations with low level auxiliary exhaust through the restroom door. (H - height above the floor; MV - mixing ventilation, DV - displacement ventilation; MV 6ACH - Case $2 \mathrm{~L}$, DV 6ACH - Case 3L, DV 4ACH - Case 4L) (a) Dimensionless air temperature $\left(\theta=\left(T-T_{s}\right) /\left(T_{e}-T_{s}\right)\right)$; (b) Air Velocity; (c) Dimensionless $\mathrm{SF}_{6}$ concentration $\left(\varepsilon=\left(C-C_{s}\right) /\left(C_{e}-C_{s}\right)\right)$ 


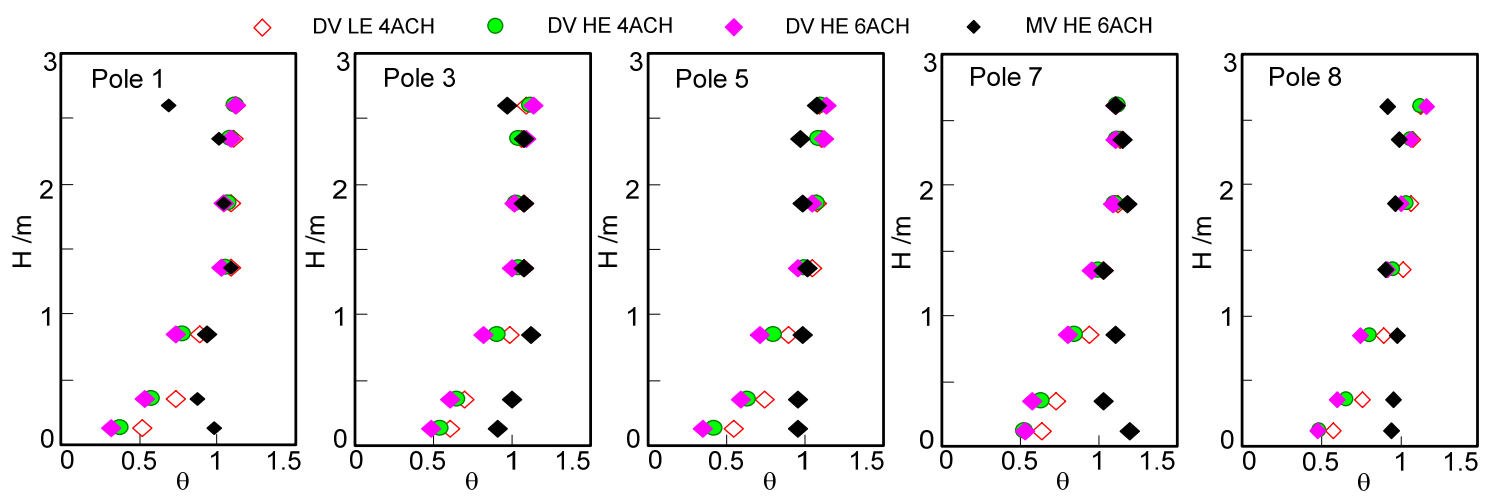

(a) Dimensionless Air Temperature $\left(\theta=\left(T-T_{s}\right) /\left(T_{e}-T_{s}\right)\right)$
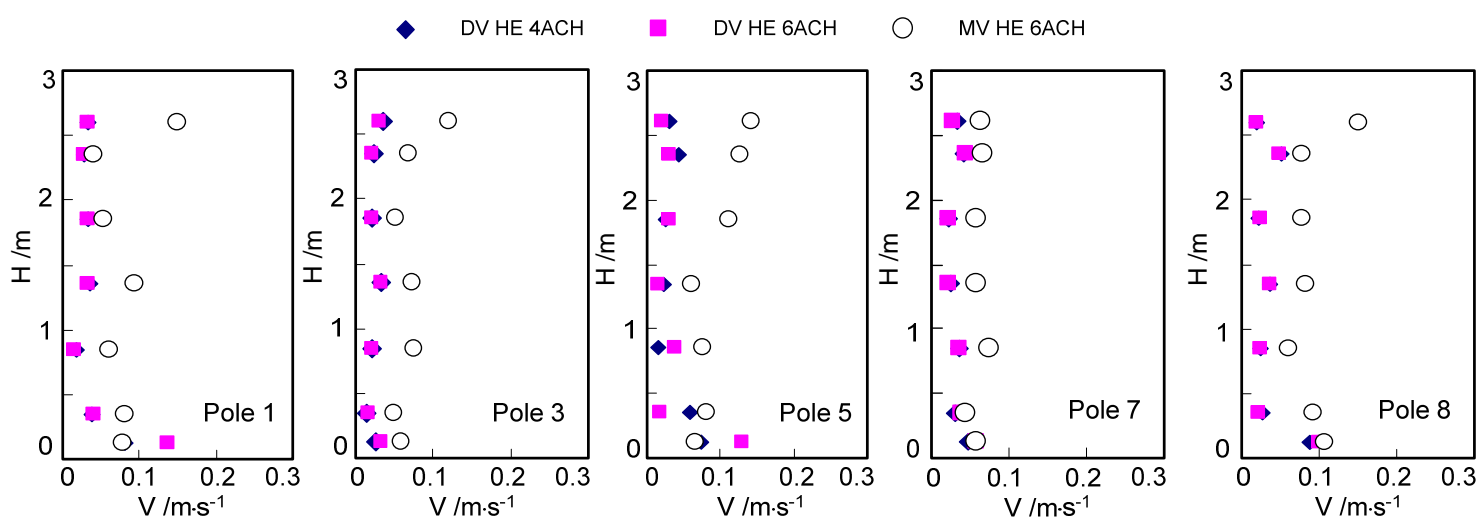

(b) Air Velocity
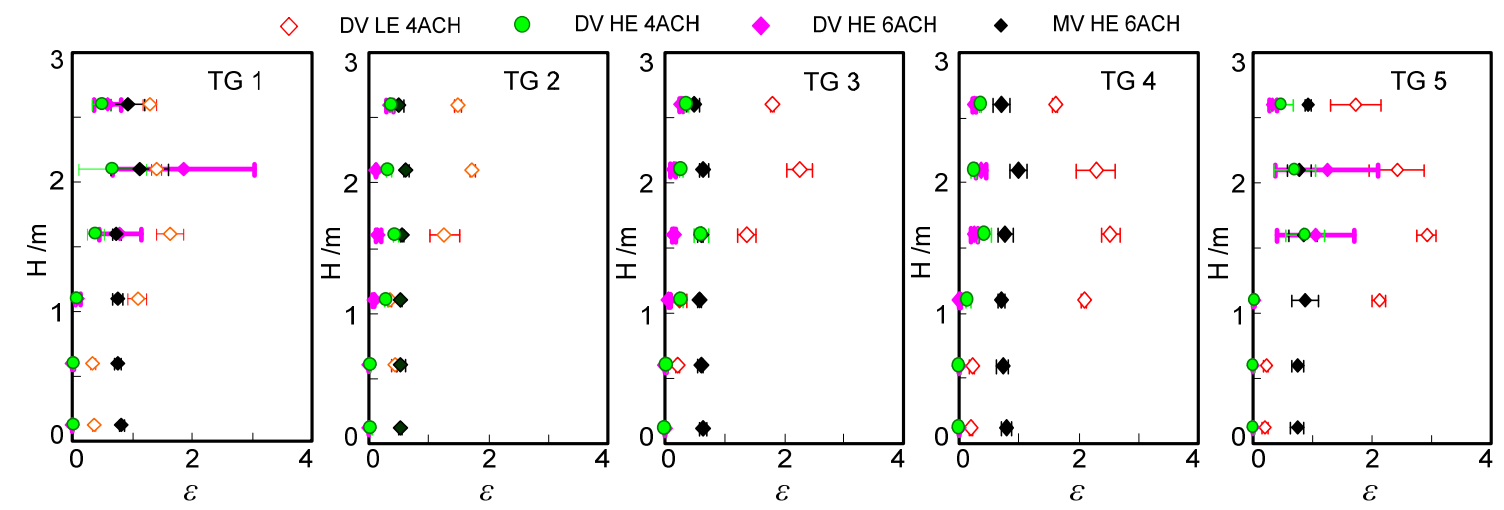

(c) Dimensionless concentration $\left(\varepsilon=\left(C-C_{s}\right) /\left(C_{e^{-}} C_{s}\right)\right)$

Fig. 7 Comparison of the displacement and mixing ventilation with high level auxiliary exhaust through the restroom door. (LE - low level exhaust, HE - high level exhaust; DV LE 4ACH - Case 4L, DV HE 4ACH - Case 3H, DV HE 6ACH - Case 2H, MV HE 6ACH - Case 1H)
(a) Dimensionless Air Temperature $\left(\theta=\left(T-T_{s}\right) /\left(T_{e}-T_{s}\right)\right)$
(b) Air Velocity
(c) Dimensionless concentration $\left(\varepsilon=\left(C-C_{s}\right) /\left(C_{e}-C_{S}\right)\right)$ 

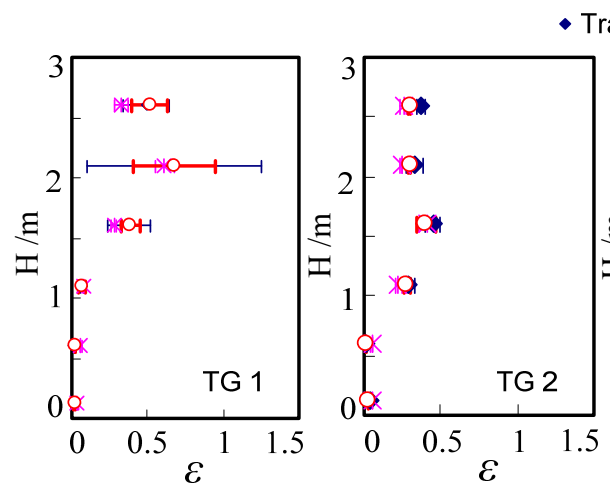

- Tracer Gas * $1 \mu \mathrm{m} \circ 3 \mu \mathrm{m}$
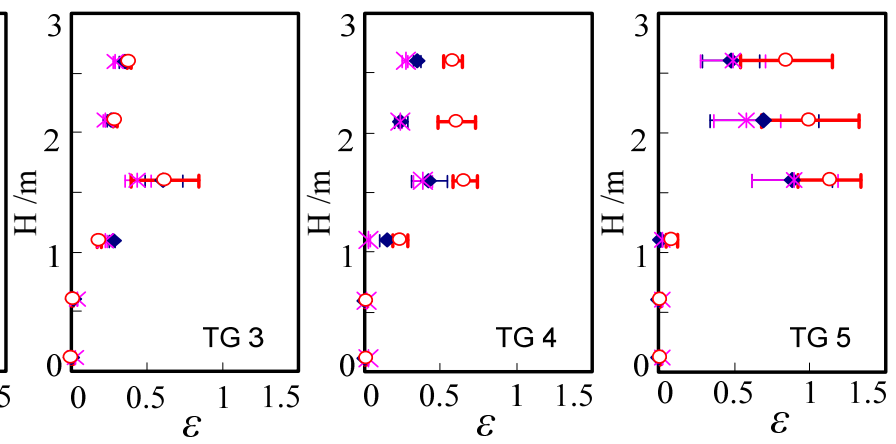

Fig. 8 Comparison of the contaminant concentration profiles in the ward by using the tracer gas (Case $3 \mathrm{H}$ ), $1 \mu \mathrm{m}$ particles (Case $4 \mathrm{H}$ ), and $3 \mu \mathrm{m}$ particles (Case $5 \mathrm{Hc}$ ). 


\section{Tables:}

Table 1. Dimensions and Power of Major Objects in the Ward

Table 2. Cases Studied in this Investigation

Table 3. Comparison of the Air Velocity at Some Locations in the Room Measured by the Omni-anemometers and the Ultra-sonic Anemometers (m/s) 
Table 1. Dimensions and Power of Major Objects in the Ward

\begin{tabular}{|c|c|c|c|c|}
\hline & $\mathrm{L} / \mathrm{cm}$ & $\mathrm{H} / \mathrm{cm}$ & $\mathrm{W} / \mathrm{cm}$ & Actual power $(\mathrm{W})$ \\
\hline Patient & $40.5(16$ in. $)$ & $183.0(72$ in. $)$ & $20.5(8$ in. $)$ & 106.25 \\
\hline Caretaker & $40.5(16$ in. $)$ & $183.0(72$ in. $)$ & $20.5(8$ in. $)$ & 110.63 \\
\hline Medical equipment & $40.0(15.7$ in. $)$ & $110.0(43.3$ in. $)$ & $40.0(15.7$ in. $)$ & 36.25 \\
\hline TV set & $43.0(17$ in. $)$ & $38.0(15$ in. $)$ & $12.0(4.7$ in. $)$ & 23.75 \\
\hline Diffuser & $55.0(21.6$ in. $)$ & $70.0(27.6$ in. $)$ & $11.0(4.3$ in. $)$ & 0 \\
\hline Bed & $228.0(89.8$ in. $)$ & $62.0(24.4$ in. $)$ & $90.0(35.4$ in. $)$ & 0 \\
\hline Main exhaust grille & \multicolumn{3}{|c|}{$25.4 \mathrm{~cm}(10$ in. $) \times 25.4 \mathrm{~cm}(10$ in. $)$} \\
\hline Exhaust grille to the restroom & \multicolumn{3}{|c|}{$30.5 \mathrm{~cm}(12 \mathrm{in}.) \times 25.4 \mathrm{~cm}(10$ in. $)$} \\
\hline
\end{tabular}

Note: L-horizontal length; H-vertical height; W-thickness.

Table 2. Cases Studied in this Investigation

\begin{tabular}{|c|c|c|c|c|c|c|}
\hline Case & Ventilation & $\begin{array}{c}\text { Auxiliary } \\
\text { exhaust location }\end{array}$ & $\begin{array}{c}\text { Flow rate } \\
(\mathrm{ACH})\end{array}$ & $\begin{array}{c}\text { Non- } \\
\text { isothermal }\end{array}$ & $\begin{array}{c}\text { Respiratory } \\
\text { mode }\end{array}$ & Contaminant \\
\hline 1L & Mixing & Low level & 6 & No & No & No \\
\hline 2L & Mixing & Low level & 6 & Yes & Breathing & Tracer-gas $\mathrm{SF}_{6}$ \\
\hline 3L & Displacement & Low level & 6 & Yes & Breathing & Tracer-gas $\mathrm{SF}_{6}$ \\
\hline 4L & Displacement & Low level & 4 & Yes & Breathing & Tracer-gas SF 6 \\
\hline 5L & Displacement & Low level & 4 & Yes & Breathing & $3.0 \mu$ particles \\
\hline 6L & Mixing & Low level & 6 & Yes & Breathing & $3.0 \mu$ particles \\
\hline 1H & Mixing & High level & 6 & Yes & Breathing & Tracer-gas $\mathrm{SF}_{6}$ \\
\hline 2H & Displacement & High level & 6 & Yes & Breathing & Tracer-gas $\mathrm{SF}_{6}$ \\
\hline $3 \mathrm{H}$ & Displacement & High level & 4 & Yes & Breathing & Tracer-gas $\mathrm{SF}_{6}$ \\
\hline 4H & Displacement & High level & 4 & Yes & Breathing & $1.0 \mu$ particles \\
\hline $5 \mathrm{Ha}$ & Displacement & High level & 4 & Yes & Breathing & Tracer-gas $\mathrm{SF}_{6}$ \\
\hline $5 \mathrm{Hb}$ & Displacement & High level & 4 & Yes & Breathing & Tracer-gas $\mathrm{SF}_{6}$ \\
\hline $5 \mathrm{Hc}$ & Displacement & High level & 4 & Yes & Breathing & $3.0 \mu$ particles, $\mathrm{SF}_{6}$ \\
\hline $6 \mathrm{Ha}$ & Mixing & High level & 6 & Yes & Breathing & Tracer-gas $\mathrm{SF}_{6}$ \\
\hline $6 \mathrm{Hb}$ & Mixing & High level & 6 & Yes & Breathing & $3.0 \mu$ particles, $\mathrm{SF}_{6}$ \\
\hline $6 \mathrm{Hc}$ & Mixing & High level & 6 & Yes & Breathing & Tracer-gas $\mathrm{SF}_{6}$ \\
\hline
\end{tabular}

Table 3. Comparison of the Air Velocity at Some Locations in the Room Measured by the Omni-anemometers and the Ultra-sonic Anemometers (m/s)

\begin{tabular}{|c|c|c|c|c|c|c|c|}
\hline \multicolumn{2}{|c|}{ Measured points } & 1 & 2 & 3 & 4 & 5 & 6 \\
\hline $\begin{array}{c}\text { Displacement } \\
\text { ventilation }\end{array}$ & $\begin{array}{c}\text { Omni-directional } \\
\text { anemometers }\end{array}$ & 0.0374 & 0.0325 & 0.0345 & 0.0229 & 0.0284 & 0.0369 \\
\cline { 2 - 8 } & Ultra-sonic anemometers & 0.0216 & 0.0494 & 0.0215 & 0.039 & 0.0217 & 0.0212 \\
\hline $\begin{array}{c}\text { Mixing } \\
\text { ventilation }\end{array}$ & $\begin{array}{c}\text { Omni-directional } \\
\text { anemometers }\end{array}$ & 0.0955 & 0.0745 & 0.0957 & 0.0727 & 0.0552 & 0.0786 \\
\cline { 2 - 8 } & Ultra-sonic anemometers & 0.0927 & 0.068 & 0.0923 & 0.0665 & 0.0408 & 0.0683 \\
\hline
\end{tabular}

